Journal of Technology and Social for Community Service (JTSCS)

Vol. 2, No. 2, September 2021, page-page. 72 81

P-ISSN: 2723-455X

E-ISSN: 2723-2026

available online at: $\underline{\text { https://ejurnal.teknokrat.ac.id/index.php/teknoabdimas }}$

\title{
PELATIHAN SPADA SEBAGAI OPTIMALISASI LMS PADA PEMBELAJARAN DI MASA PANDEMI COVID 19
}

\author{
Ahmad Ari Aldino ${ }^{1}$, Very Hendra ${ }^{2}$, Dedi Darwis ${ }^{3}$ \\ Program Studi Informatika, Fakultas Teknik dan Ilmu Komputer, Universitas Teknokrat Indonesia \\ Program Studi Pendidikan Matematika, Fakultas Sastra dan Ilmu Pendidikan, Universitas Teknokrat Indonesia \\ Program Studi Sistem Informasi Akuntansi, Fakultas Teknik dan Ilmu Komputer, Universitas Teknokrat \\ Indonesia
}

Email : $\underline{\text { aldino@teknokrat.ac.id }{ }^{1}}$, veryhendra@teknokrat.ac.id ${ }^{2}$, darwisdedi@teknokrat.ac.id ${ }^{3}$

\begin{abstract}
Received: (6 Agustus 2021)
Accepted: (10 September 2021)

Abstract

E-learning-is one solution so that the learning process during the Covid-19 pandemic continues. Elearning can facilitate teachers and students in implementing the distance learning process (PJJ). The problem is that not all applications used for Distance Learning (PJJ) have the same standardization both in terms of filling out materials, assignments and assessing student learning outcomes. Therefore, a Learning Management System (LMS) is needed to standardize both in terms of material, assignments and assessment of student learning outcomes, so that the learning process can be achieved in accordance with the objectives. To overcome this problem, the Community Service Team of the Indonesian Technocrat University in collaboration with the Management of SMA Negeri 1 Metro Kibang implemented a Leanring Management System (LMS) in the learning process during the pandemic. The implementation of the Learning Management System (LMS) is implemented in the form of SPADA training for the Principal and all management of SMAN 1 Metro Kibang. The purpose of this training is so that the Principal can monitor learning activities and teachers can apply the Learning Management System (LMS) in the learning process during the pandemic. This training was attended by 28 teachers of SMA Negeri 1 Metro Kibang. The results in this activity are 91.964\% of SMA N 1 Metro Kibang teachers can apply the Learning Management System (LMS) in the form of using the SPADA application in the learning process, the value is obtained from the results of giving a questionnaire after the training. In addition, the application of the Learning Management System (LMS) in the form of using SPADA is also beneficial for school principals in monitoring teacher performance in the learning process during the COVID-19 Pandemic
\end{abstract}

Published : (15 September 2021)

Keywords: E-learning LMS, Spada,

\begin{abstract}
Abstrak
E-learning merupakan salah satu solusi agar proses pembelajaran selama pandemi Covid-19 tetap berjalan. E-learning dapat memudahkan guru dan siswa dalam melaksanakan proses pembelajaran jarak jauh (PJJ). Permasalahannya adalah tidak semua aplikasi yang digunakan untuk Pembelajaran Jarak Jauh(PJJ) memiliki standarisasi yang sama baik dari segi pengisian materi, penugasan dan penilaian hasil belajar siswa. Oleh karena itu diperlukan Learning Managemen System(LMS) untuk menstandarisasi baik dari segi materi, penugasan dan penilaian hasil belajar siswa, agar proses pembelajaran dapat tercapai sesuai dengan tujuan. Untuk mengatasi permasalahan tersebut maka Tim Pengabdian Kepada Masyarakat Universitas Teknokrat Indonesia berkerja sama dengan pihak Manajemen SMA Negeri 1 Metro Kibang menerapkan Leanring Mangemen Systerm (LMS) pada proses pembelajaran selama pandemi. Penerapan Learning Managemen System (LMS) tersebut di implementasikan dalam bentuk pelatihan SPADA untuk Kepala Sekolah dan semua pihak manajemen SMA NegeriN 1 Metro Kibang. Tujuan dari pelatihan ini adalah agar Kepala Sekolah dapat memonitoring kegiatan pembelajaran dan guru dapat menerapkan Learning Managemen System (LMS) pada proses pembelajaran selama pandemi. Pelatihan ini di ikuti oleh 28 guru SMA Negeri 1 Metro Kibang. Hasil dalam
\end{abstract}


kegiatan ini yaitu 91.964 \%guru SMA N 1 Metro Kibang dapat menerapkan Learning Managemen System(LMS) berupa penggunakan aplikasi SPADA pada proses pembelajaran, nilai tersebut diperoleh dari hasil pemberian angket setelah pelatihan. Selain itu penerapan Learning Managemen System(LMS) berupa pemafaatan SPADA juga bermanfaat bagi Kepala Sekolah dalam memonitoring kinerja guru pada proses pembelajaran selama masa pandemi covid-19

Kata Kunci: E-learning LMS, Spada,

\section{To cite this article:}

Ahmad Ari Aldino, Very Hendra, Dedi Darwis. (2021). PELATIHAN SPADA SEBAGAI OPTIMALISASI LMS PADA PEMBELAJARAN DI MASA PANDEMI COVID 19. Journal of Technology and Social for Community Service (JTSCS), Vol(2), 71-81.

\section{PENDAHULUAN}

Pemanfaatan e-learning di masa pandemi Covid-19 merupakan salah satu solusi agar proses pembelajaran tetap berjalan. Manfaaat e-learning diantaranya yaitu mempermudah guru dalam menyampaikan materi dan mempermudah siswa dalam mengakses materi pelajaran di masa pandemi Covid-19. Namun permasalanya yaitu setiap guru menggunakan aplikasi online yang berbeda untuk menyampaikan materi kepada siswa, sehingga tidak ada standarisasi yang sama dalam meyampaikan materi, penugasan dan penilaian hasil kerja siswa. oleh karena itu setiap sekolah harus mempunyai strategi manajemen pembelajaran yang tepat agar proses pembelajaran dapat berjalan dan tujuan dari pembelajaran dapat tercapai.

Belajar adalah suatu proses yang dilakukan secara sadar dengan perencanaan yang tepat agar tujuan pembelajaran dapat tercapai, oleh karena itu diperlukan strategi dalam mempersiapkan proses pembelajaran, baik dari segi metode, media dan kesesuian kurikulum yang berlaku. Pemilihan $e$ learning sebagai media pembelajaran di masa pandemi adalah pilihan yang tepat.(Very, 2021) bahwa dengan pemilihan media yang tepat untuk pembelajaran dapat mempermudah baik guru maupun siswa dalam melakukan proses pembelajaran, Selain itu media yang dibuat hendaknya sesuai dengan karakteristik kurikulum yang berlaku(Saputra, Pasha, \& Afriska, 2020). Media pembelajaran dapat berupa online maupun ofline dan disesuaikan dengan karakteristik siswa (Saputra \& Pasha, 2021). Keunggulan dari e-learning adalah dapat meningkatkan kompetensi guru dalam mengajar, hal tersebut sesuai dengan hasil penelitian (Harahap \& Alpi, 2017) yang menyatakan bahwa dengan e-learning kompetensi guru secara pedagogik. Salah satu penerapan e-learning yaitu dengan menggunakan SPADA pada proses pembelajaran

SPADA(Sistem Pembelajaran Dalam Jaringan) merupakan aplikasi penunjang kegiatan sekolah maupun pendidikan secara online dengan memberikan berbagai layanan yang dapat memudahkan aktivitas siswa, guru, maupun tenaga ahli sekolah dalam menjalankan kegiatan belajar mengajar yang berbasis online. Penggunaan SPADA dalam prosese pembelajaran diperlukan strategi baik dalam pengisian konten materi, penugasan dan penilaian hasil belajar siswa, oleh karena itu perlu Learning Managemen System (LMS) dalam merancang dan pengembangan SPADA agar tujuan dari pembelajaran dapat tercapai dengan maksimal. Hal tersebut sesuai degan hasil penelitian (Saputro \& Susilowati, 2019) yang menyatakan bahwa dengan konsep pembelajaran yang disusun secara sistematis di LMS SPADA akan membantu mahasiswa dalam menyelesaikan penugasan perkuliahan.

Kelebihan dari aplikasi SPADA yaitu terdapatnya standarisasi dalam pengisian konten pembelajaran dari segi materi, tugas, kuis dan penilaian hasil kerja siswa, dan memudahkan Kepala Sekolah dalam memonitor kinerja guru di dalam melakukan proses pembelajaran selama pandemi. Selain itu aplikasi SPADA dapat menambah pengalaman dalam proses pembelajaran (Etno-stem, Reffiane, \& Saptono, 2020). Pembelajaran secara daring dengan Learning Managemen System yang tepat dapat menambah kemandirian siswa (Rabiman, Nurtanto, \& Kholifah, 2020) Hasil penelitian lain tentang mandaaf SPADA yaitu penelitian (Darwis, Saputra, \& Ahdan, 2020) terkait penerapan aplikasi SPADA berkesimpulan bahwa pihak sekolah lebih mudah mengontrol proses pembelajaran secara daring dan setiap guru mempunyai kesamaan standar penyampaian konten isi kepada siswa 
baik dari segi materi, penugasan dan penilaian. Selain itu penelitian terkait penggunaan SPADA yang telah dilakukan oleh (Sulistiani \& Saputra, 2020) yaitu bahwa aplikasi SPADA dapat membantu pihak sekolah dalam melakukan pengawasan pembelajaran selama pandemi Covid -19.

SMA Negeri 1 Metro Kibang merupakan SMA Negeri yang berlokasi di Jl. Raya Metro Kibang,, Kabupaten Lampung Timur. Sekolah tersebut selalu berbenah dan berinovasi agar proses pembelajaran selama pandemi dapat berjalan sesuai dengan tujuan pendidikan di SMA Negeri 1 Metro Kibang. Berdasarkan wawancara dengan kepala sekolah dan wakil bidang kurikulum, bahwa guru menggunakan aplikasi grup whatsApp dan google calasrom dalam proses pembelajaran di masa pandemi Covid-19, hal tersebut membuat standarirasi penyampaian yang diberikan guru kepada siswa berbeda, baik dari segi isi, penugasan dan penilaian hasil kerja siswa, selain itu Kepala Sekolah menyampaikan bahwa sulitnya memonitoring dewan guru tekait pelaksanaan tugas memberikan materi selama pandemi Covid-19. Berdasarkan permasalahan tersebut maka tim Pengabdian Kepada Masyarakat dari Universitas Teknokrat Indonesia memberikan solusi terkait penerapan Learning Managemen System (LMS) dengan pada aplikasi SPADA di SMA Negeri 1 Metro Kibang, hal tersebut diberikan sebagai solusi karena sebelumnya tim Pengabdian Kepada Masarakat Universitas Teknokrat Indonesia telah melakukan program yang sama dengan permasalahan yang sama dan berhasil mengatasi permasalahan tersebut, program sebelumnya dilaksanakan di SMK Yayasan Pemuda Indonesia Tanjung Bintang Lampung Selatan, dan SMK 7 Bandar Lampung serta di SMA Bina Mulya Gading Rejo, berkat penerapan aplikasi SPADA pada proses pembelajaran di masa pandemi, Kepala Sekolah dapat memonitoring aktivitas guru dalam melaksanakan tugasnya yaitu memberikan materi kepada siswa melalui daring selama masa pandemi Covid-19, dan dewan guru telah memiliki standarisasi yang sama dalam pemberian materi, penugasan dan penilaian.

\section{METODE PELAKSANAAN \\ Tempat dan Waktu}

Pelatihan penerapan Sistem Pembelajaran dalam Jaringan sebagai optimalisasi Learning Managemen System (LMS) pada pembelajaran dilaksanakan pada tanggal 27 dan 28 April 2021 di SMA Negeri 1 Metro Kibang

\section{Khalayak Sasaran}

Kegiatan pelatihan ini diikuti oleh 28 peserta yang terdiri dari dewan guru SMA Negeri 1 Metro Kibang

\section{Teknik Pengumpulan Data}

Pada pelatihan ini digunakan kuisioner untuk keperluan pengumpulan data, hal tersebut bertujuan mengumpulkan data untuk mengetahui peningkatan kemampuan dewan guru SMA Negeri 1 Metro Kibang dalam menerapkan Learning Managemen System (LMS) dalam bentuk penggunaan SPADA pada proses pembelajaran selama pandemi Covid-19

\section{Metode Pengabdian}

Penerapan Learning Managemen System (LMS) berupa pelatihan penggunaan aplikasi SPADA pada proses pembelajaran selama pandemi ini merupakan salah satu bentuk dari pengabdian kepada masyarakat Universitas Teknokrat Indonesia, dengan memberikan pelatihan SPADA nantinya dapat bermanfaat bagi proses pembelajaran terlebih di masa pandemi Covid-19.

Tahapan pelatihan SPADA di SMA Negeri 1 Metro Kibang dibagi menjadi beberapa tahap pelatihan penerapan Learning Managemen System (LMS) berupa penggunaan SPADA dalam proses pembelajaran seperti pada Gambar 1 


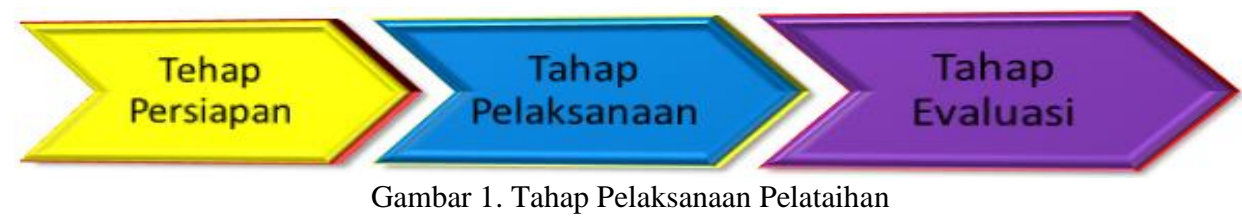

Berikut adalah penjelasan alur kegiatan berdasarkan Gambar 1

\section{Tahap Persiapan}

- Pada tahap ini dilakukan pengumpulan data berupa informasi yang akan digunakan untuk membangun aplikasi $S P A D A$ yang terdiri dari jenis mata pelajaran, nama guru dan siswa serta mata pelajaran yang diampu setiap guru

- Tahap kedua dari persiapan yaitu membuat standarisasi yang nantinya akan di gunakan pada konten SPADA diantaranya yaitu: standar penggunaan aplikasi, standar content materi, standar pretest dan posttest, standar tugas siswa, standar penilaian tugas siswa. Pada tahap ini tim PKM Universitas Teknokrat Indonesia berkolaborasi dengan pihak manajemen SMA Negeri 1 Metro Kibang dalam penentuan standar pembelajaran yang sesuai dengan standar SMA Negeri 1 Metro Kibang

- Tahap ketiga dari persiapan yaitu mengembangkan aplikasi SPADA sesuai dengan kebutuhan yang telah disepakati pihak manajemen SMA Negeri 1 Metro Kibang berdasarkan persiapan pada tahap kedua.

\section{Tahap Pelaksanaan}

Setelah aplikasi SPADA selesai dikembangkan sesuai kebutuhan yang telah disepakati, maka tahap selanjutnya adalah memberikan pelatihan SPADA kepada guru SMA Negeri 1 Metro Kibang, dengan tujuan guru dapat mengoperasikan aplikasi SPADA dan menerapkannya pada proses pembelajaran selama masa pandemi. Pelatihan yang diberikan yaitu terkait dengan bagaimana mengisi content SPADA baik dari segi materi, penugasan dan penilaian hasil belajar siswa berdasarkan standar yang telah di tetapkan oleh pihak manajemen sekolah SMA Negeri 1 Metro Kibang

\section{Tahap Evaluasi}

Pada tahapan ini dilakukan untuk mengukur peningkatan pengetahuan guru dan kesusksesan hasil pelatihan SPADA di SMA Negeri 1 Metro Kibang, evaluasi dilakukan dengan memberikan kuisioner kepada responden berjumlah 28 orang guru SMA Negeri 1 Metro Kibang. Kuisioner diberikan sebelum dan setelah dilaksanakan pelatihan

\section{HASIL DAN PEMBAHASAN}

\section{Kebutuhan Data}

Untuk pengembangan aplikasi SPADA SMA Negeri 1 Metro Kibang sebagai realisasi penerapan Learning Managemen System(LMS) data awal yang dibutuhkan yaitu terkait dengan mata pelajaran di tiap jurusan. Selanjutnya data mata pelajaran dikelompokkan berdasarkan kelas. Berikut adalah sampel dari pengelompokan mata pelajaran berdasarkan kelas dan jurusan (sampel kelas X Jurusan MIPA dan kelas XI Jurusan IPS) 
Tabel 1. Pola pengelompokan Mata Pelajaran

\begin{tabular}{|c|c|c|c|}
\hline No & Kelas & Jurusan & Mata Pelajaran \\
\hline \multirow{11}{*}{1} & \multirow{11}{*}{$\mathrm{X}$} & MIPA & Penjas \\
\hline & & & PAI \\
\hline & & & Matematika \\
\hline & & & Seni Budaya \\
\hline & & & Pendidikan Anti Korupsi \\
\hline & & & Bahasa Lampung \\
\hline & & & Bahasa Indonesia \\
\hline & & & Fisika \\
\hline & & & Biologi \\
\hline & & & Kimia \\
\hline & & & PKN \\
\hline \multirow{10}{*}{2} & \multirow{10}{*}{$\mathrm{X}$} & IPS & Penjas \\
\hline & & & PAI \\
\hline & & & Matematika \\
\hline & & & Seni Budaya \\
\hline & & & Pendidikan Anti Korupsi \\
\hline & & & Bahasa Lampung \\
\hline & & & Bahasa Indonesia \\
\hline & & & Geografi \\
\hline & & & Sejarah \\
\hline & & & Ekonomi \\
\hline
\end{tabular}

Tujuan dari pengelomppokan mata pelajaran berdasarkan jurusan adalah untuk mempermudah pihak pengelola SPADA yaitu manajemen SMA Negeri 1 Metro Kibang dalam pengisian data guru pengampu mata pelajaran sesuai dengan jurusan dan mempermudah dalam memonitoring kegiatan pembelajaran

\section{Learning Managemen System pada Pengisian Konten SPADA}

Standarisasi pengisian konten SPADA dibuat berdasarkan kesepakatan pihak manajemen SMA Negeri 1 Metro Kibang, standarisasi pengisian konten ini disesuaikan dengan standarisasi yang diterapkan di SMA Negeri 1 Metro Kibang dalam proses pembelajaran. Berikut adalah Standarisasi pembelajaran di SMA Negeri 1 Metro Kibang disajikan pada Tabel 2

Tabel 2. Standar Pengisian Konten SPADA SMA Negeri 1 Metro Kibang

\begin{tabular}{|c|c|c|}
\hline No & Standar Pengisian Konten & Keterangan \\
\hline 1 & Salam Pembuka & $\begin{array}{l}\text { Sapaan guru sebelum memulai pelajaran dapat berisi tentang gambaran materi yang akan di } \\
\text { ajarkan pada tiap pertemuan }\end{array}$ \\
\hline 2 & Materi Pelajaran & Membahas secara garis besar isi materi yang akan disampaikan guru kepada siswa \\
\hline 3 & SK dan KD & $\begin{array}{l}\text { Memuat standar kompetensi dan kompetensi dasar terkait materi yang akan diberikan kepada } \\
\text { siswa }\end{array}$ \\
\hline 4 & Capaian Pembelajaran & Capaian pembelajaran memuat tujuan yang akan dicapai pada setiap pelajaran \\
\hline 5 & Indikator & Langkah yang akan digunakan untuk mengukur dalam mencapai tujuan tiap materi \\
\hline 6 & Referensi & Sumber yang digunakan guru terkait materi yang diberikan kepada siswa \\
\hline 7 & Isi Materi Pembelajaran & $\begin{array}{l}\text { Berisi materi pelajaran baik dalam bentuk slide power point, pdf, video, modul praktikum, } \\
\text { tutorial dan sumber lain yang dapat dijadikan sebagai materi pelajaran untuk proses } \\
\text { pembelajaran }\end{array}$ \\
\hline 8 & Video & $\begin{array}{l}\text { Video berisi tutorial terkait penjelasan guru, video dapat mengambil referensi dari youtub, atau } \\
\text { vidio rekaman guru terkait materi yang akan diberikan kepada siswa }\end{array}$ \\
\hline 9 & Forum Diskusi & Content ini berisi tentang diskusi terkait materi yang telah diajarkan tiap pertemuan. \\
\hline 10 & Pre dan Post tes & $\begin{array}{l}\text { Pre test dan post tes ddigunakan untuk mengukur sejauh mana perkembangan siswa terkait } \\
\text { materi yang diajarkan tiap pertemuan }\end{array}$ \\
\hline 11 & Penugasan & $\begin{array}{l}\text { Penugasa berisi tugas tiap pertemuan, dengan tujuan untuk menambah dan memantapkan } \\
\text { konsep materi yg telah diberikan }\end{array}$ \\
\hline 12 & Salam Penutup & $\begin{array}{l}\text { Salam penutup berisi arahan tentang tiap pertemuan dan tempat memberikan informs terkait } \\
\text { materi yang akan diajarkan pada pertemuan berikutnya }\end{array}$ \\
\hline
\end{tabular}




\section{Standari Evaluasi}

Evaluasi sangat diperlukan dalam proses pembelajaran salah satu tujuannya adalah untuk mengetahui produktifitas kinerja guru dalam melaksanakan tugasnya, tentunya evaluasi harus sesuai dengan kriteria tertentu. Pada tahap evaluasi ini merupakan tugas dari manajemen SMA Negeri 1 Metro Kibang dalam memonitoring dan mengontrol kegiatan pembelajaran secara online. Acuannya adalah pada Tabel 2. Jika guru telah memenuhi semua poin standar yang telah ditentukan pada Tabel 2, maka guru tersebut telah memenuhi standar proses pembelajaran di SMA Negeri 1 Metro Kibang

\section{Pengembangan aplikasi SPADA SMA Negeri 1 Metro Kibang}

Setelah dilakukan kesepakatan dengan pihak manajemen SMA Negeri 1 Metro Kibang terkait standar pengisian konten pembelajaran, maka tahap selanjutnya yaitu mengembangkan aplikasi SPADA dengan menggunakan Moodle 3 berdasarkan apa yang telah disepakati oleh pihak manajemen SMA Negeri 1 Metro Kibang. Berikut adalah contoh tampilan SPADA yang telah dikembangkan.

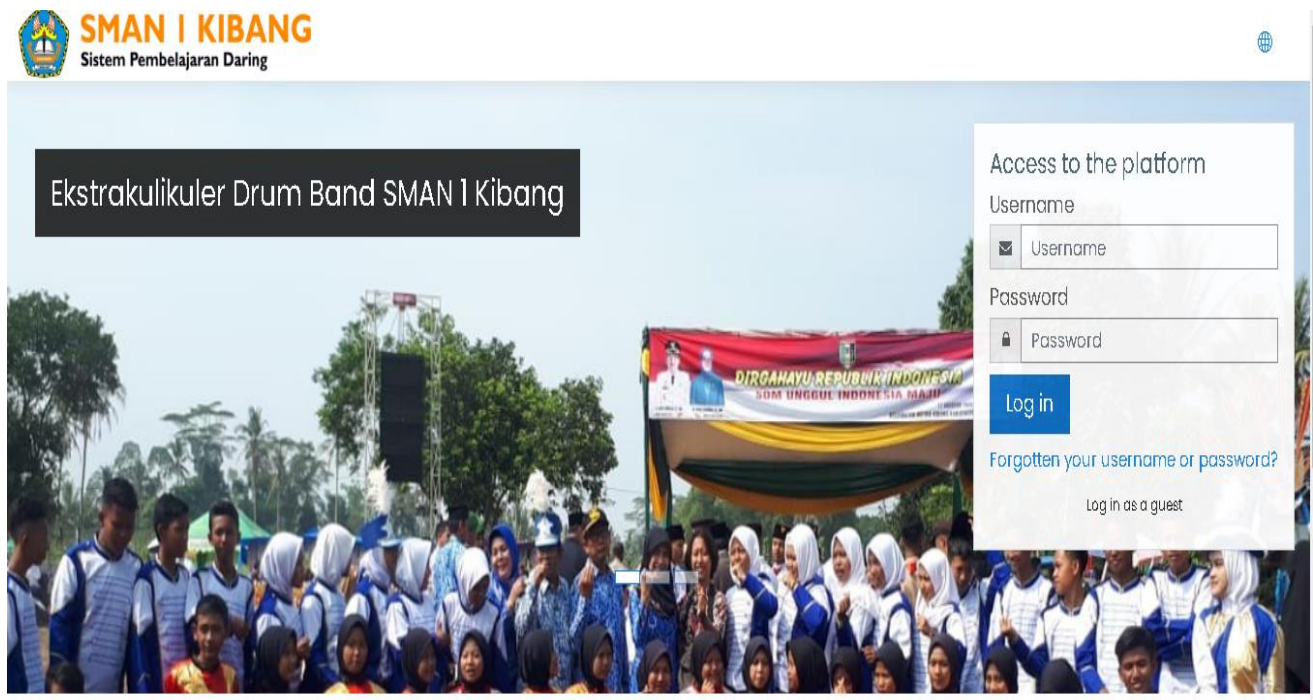

Gambar 2. Tampilan SPADA SMA Negeri 1 Metro Kibang

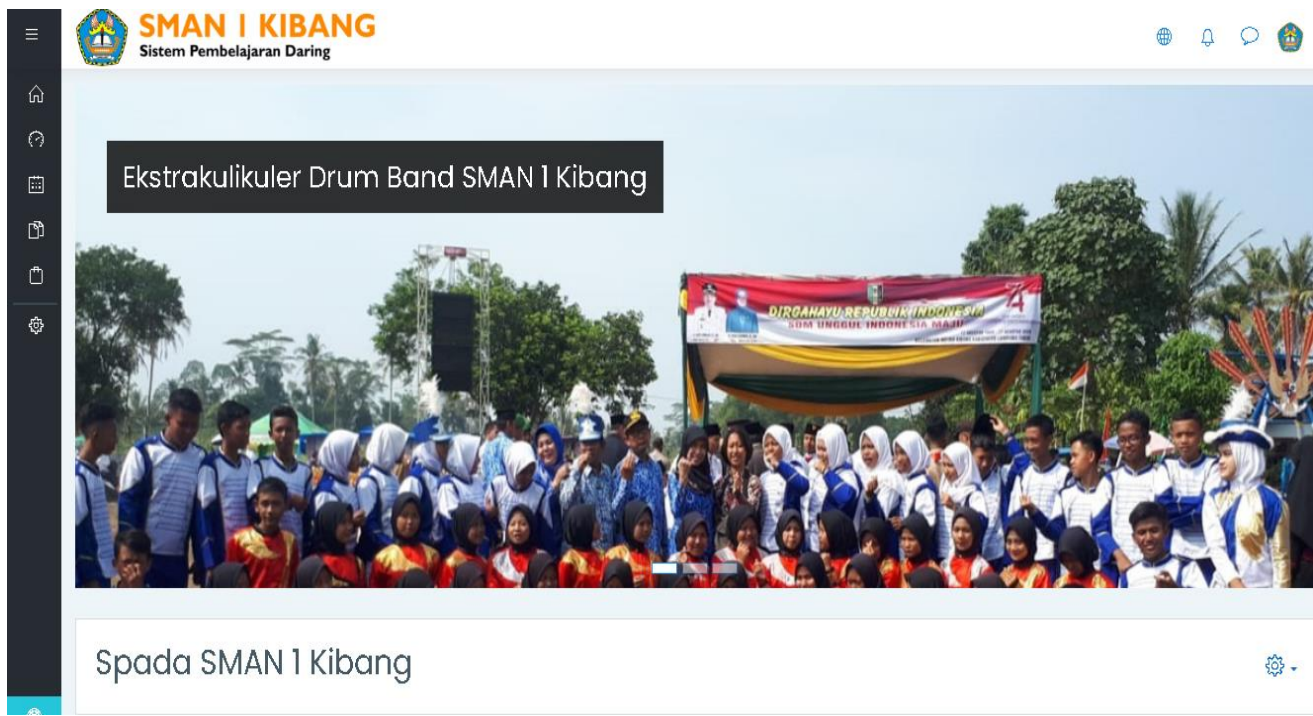

Gambar 3. Tampilan awal SPADA SMA Negeri 1 Metro Kibang 


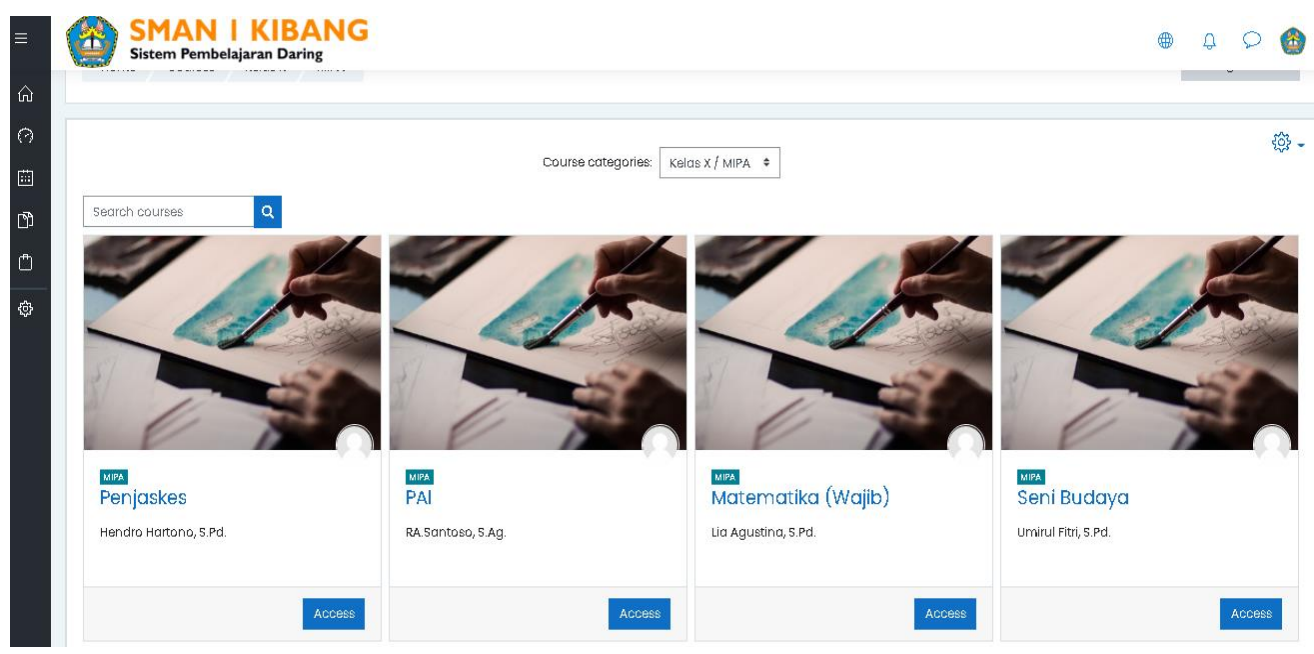

Gambar 4. Tampilan konten Materi SPADA SMA Negeri 1 Metro Kibang

\section{Kegiatan pelatihan SPADA}

Kegiatan ini bertujuan untuk memberikan pengetahuan tentang teknis penggunaan SPADA pelatihan ini diberikan kepada Kepala Sekolah, Wakil Kepala sekolah dan semua pihak manajemen SMA Negeri 1 Metro Kibang dengan total peserta sebanyak 28 orang. Pelatihan dilakukan selama 2 hari yaitu tanggal 27 dan 28 April 2021. Kegiatan pelatihan seperti pada Gambar 5 dan 6

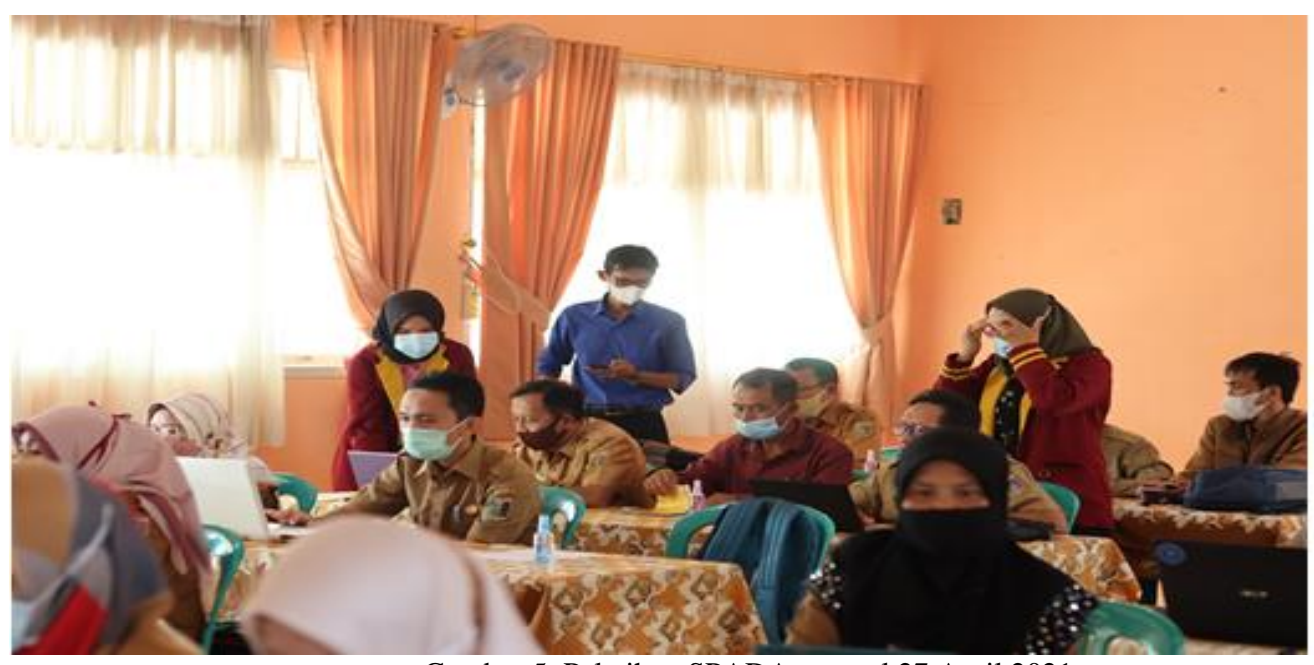

Gambar 5. Pelatihan SPADA tanggal 27 April 2021 


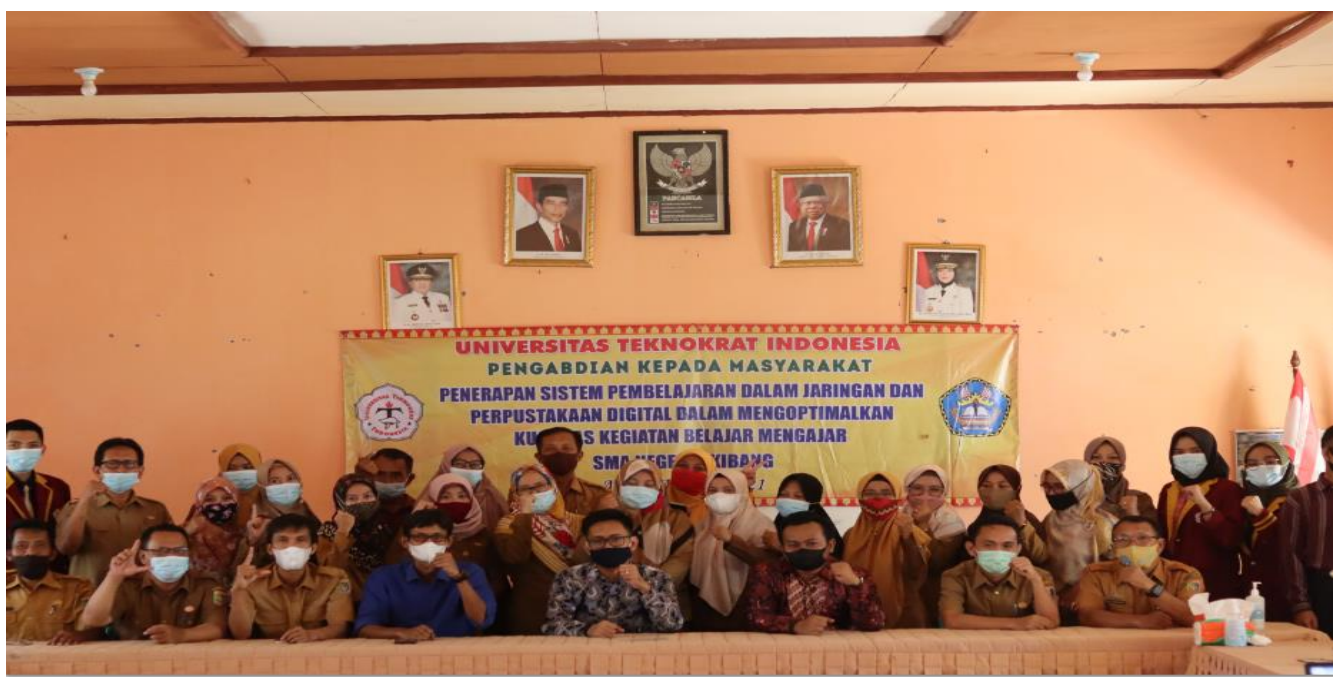

Gambar 6. Pelatihan SPADA tanggal 28 April 2021

\section{Evaluasi SPADA}

Evaluasi dilalakukan untuk mengetahui peningkatan pengetahuan guru dan pihak manajemen SMA Negeri 1 Metro Kibang dalam menerapkan Learning Managemen System(LMS) pada Penggunaan aplikasi SPADA untuk kegiatan pembelajaran di masa pandemi Covid-19. Evaluasi dilakukan dengan memberikan kuisioner sebelum dan sesudah pelatihan. Kuisioner didesain untuk mengetahu peningkatan kemampuan terkait pemanfaatan SPADA pada proses pembelajaran. Adapun hasil dari kuisioner tersebut seperti pada tabel berikut :

Tabel 3. Hasil Kuisioner Sebelum dan Sesudah Pelatihan

\begin{tabular}{|c|c|c|c|c|c|}
\hline No & Uraian Pertanyaan & $\begin{array}{l}\text { Sebelum } \\
\text { pelatihan }\end{array}$ & Rata-Rata & $\begin{array}{r}\text { Sesudah } \\
\text { pelatihan }\end{array}$ & Rata-Rata \\
\hline 1 & Apakah Bapak/lbu mengetahui tentang e-learning ? & 25 & 89.286 & 27 & 96.429 \\
\hline 2 & Apakah Bapak/Ibu mengetahui tentang SPADA? & 6 & 21.429 & 27 & 96.429 \\
\hline 3 & $\begin{array}{l}\text { Apakah Bapak/Ibu mengetahui tentang cara membuat standar } \\
\text { pembelajaran online yang baik? }\end{array}$ & 7 & 25.000 & 27 & 96.429 \\
\hline 4 & $\begin{array}{l}\text { Apakah Bapak/Ibu mengetahui cara menyisipkan video ke dalam } \\
\text { aplikasi pembelajaran online? }\end{array}$ & 7 & 25.000 & 26 & 92.857 \\
\hline 5 & $\begin{array}{l}\text { Apakah Bapak/Ibu mengetahui cara membuat forum diskusi secara } \\
\text { online untuk kegiatan belajar mengajar }\end{array}$ & 10 & 35.714 & 26 & 92.857 \\
\hline 6 & $\begin{array}{l}\text { Apakah Bapak/lbu mengetahui cara membuat soal ujian pada } \\
\text { aplikasi pembelajaran online? }\end{array}$ & 11 & 39.286 & 24 & 85.714 \\
\hline 7 & $\begin{array}{l}\text { Apakah Bapak/Ibu mengetahui cara pengelolaan Google Drive } \\
\text { untuk mendukung kegiatan belajar mengajar online? }\end{array}$ & 13 & 46.429 & 24 & 85.714 \\
\hline \multirow[t]{2}{*}{8} & $\begin{array}{l}\text { Apakah bapak/ibu mengetahui cara merekap nilai ujian secara } \\
\text { otomatis pada e-learning? }\end{array}$ & 9 & 32.143 & 25 & 89.286 \\
\hline & & 88 & $39.286 \%$ & 208 & $91.964 \%$ \\
\hline
\end{tabular}

Penerapan Learning Managemen System (LMS) di SMA Negeri 1 Metro Kibang yang di realisasikan dalam bentuk kegiatan pelatihan aplikasi SPADA merupakan bukti bahwa SMA Negeri 1 Metro Kibang selalu berbenah dan berinovasi dalam proses pembelajaran terlebih di masa pandemi Covid 19 ini agar tujuan dari pembelajaran dapat tercapai. Pemanfaatan media yang tepat dalam proses pembelajaran sangatlah penting, agar tujuan dari pembelajaran dapat tercapai, hal tersebut sesuai dengan hasil penelitian (Saputra \& Permata, 2018), selain itu media yang disusun dan dikemas secara menarik dapat meningkatkan aktivitas belajar siswa(Wicaksana, Kuniasari, Sudiatmi, No, \& Sukoharjo, 2021). Selain meningkatkan aktivitas, media pembelajaran online yang disajikan secara menarik dapat meningkatkan minat belajar siswa (Sulistiani et al., 2020).Dengan pemanfaatan SPADA yang telah dikembangkan oleh tim Pengabdian Masyarakat Universitas Teknokrat Indonesia SMA Negeri 1 Metro Kibang telah menerapkan dan menjalankan pembelajaran sesuai dengan standarisasi 
pembelajaran. Standarisasi baik dari segi materi, penugasan, dan penilaian hasil belajar siswa, dari hal tersebut berarti bahwa SMA Negeri 1 Metro Kibang telah Learning Managemen System (LMS) sesuai dengan yang diharapkan dari pihak sekolah, penerapan tersebut terimplikasi pada pemanfaatan SPADA yang telah dikembangkan oleh Tim Pengabdian Masyarakat Universitas Teknokrat Indonesia. Dengan pemanfaatan manajemen pembelajaran yang baik, akan mempermudah guru dan siswa dalam proses pembelajaran selama pandemi Covid-19, hal tersebut sesuai dengan hasil penelitian yang telah dilakukan oleh (Fitriani, 2020) bahwa dengan mereapkan manajemen pempelajaran yang baik dapat mempermudah guru dalam menyampaikan pembelajaran di masa pandemi.

\section{KESIMPULAN}

Berdasarkan pemamaran hasil pelatihan, dapat disimpulkan bahwa berdasarkan kuisioner yang telah diberikan kepada guru sebelum dan setelah pelatihan diperoleh data berupa peningkatan pengetahuan terkait penggunaan aplikasi SPADA, selain itu guru di SMA Negeri 1 Metro Kibang telah menerapkan Learning Managemen System (LMS) pada proses pembelajaran, hal tersebut telihat pemanfaatan SPADA dalam proses pembelajaran daring, namun belum semua guru dapat mengoperasikan SPADA secara baik, Hal tersebut terlihat dari hasil angket belum mencapai nilai maksimal 100\%. Dari hasil angket sebelum pelatihan 39.286\% dan sesudah diperoleh $91.964 \%$, manun tim Pengabdian Teknokrat Indonesia tetap melakukan pendampingan dengan cara menjawab pertanyaan via grup whatsaap terkait kendala yang dihadapi guru SMA Negeri 1 Metro Kibang dalam mengoperasikan aplikasi SPADA. Namun secara garis besar tujuan dari pelatihan ini telah tercapai yaitu telah tereasilasi pemanfaatan aplikasi yang mempunyai standarisasi proses pembelajaran baik dari segi pengisian materi, penugasan dan penilaian hasil belajar siswa, serta pihak manajemen dapat memonitoring kegiatan pembelajaran yang dilakukan oleh dewan guru selama pandemi Covid melalui aplikasi SPADA yang telah dikembangkan

\section{UCAPAN TERIMA KASIH}

Penulis mengucapkan terimakasih kepada Universitas Teknokrat Indonesia yang telah memberikan dukungan financial terhadap kegiatan Pengabdian Kepada Masyarakat di SMA Negeri 1 Metro Kibang

\section{REFERENSI/DAFTAR PUSTAKA}

Darwis, D., Saputra, V. H., \& Ahdan, S. (2020). Peran Sistem Pembelajaran Dalam Jaringan ( SPADA ) Sebagai Solusi Pembelajaran pada Masa Pendemi Covid-19 di SMK YPI Tanjung Bintang. Seminar Nasional Hasil Penelitian Dan Pengabdian 2020 IBI DARMAJAYA, 36-45.

Fitriani, Y. (2020). Analisa Pemanfaatan Learning Management System (Lms) Sebagai Media Pembelajaran Online Selama Pandemi Covid-19. Journal of Information System, Informatics and Computing, 4(2), 1. https://doi.org/10.52362/jisicom.v4i2.312

Harahap, S. H., \& Alpi, M. F. (2017). E-ELEARNING DALAM MENINGKATKAN KOMPETENSI MENGAJAR DOSEN DI PERGURUAN TINGGI DI KOTA MEDAN. JKBM (JURNAL KONSEP BISNIS DAN MANAJEMEN), 4(1), 42-49.

Rabiman, R., Nurtanto, M., \& Kholifah, N. (2020). Design and Development E-Learning System by Learning Management System (LMS) in Vocational Education. Online Submission, 9(1), 1059-1063.

Reffiane, F., \& Saptono, S. (2020, June). Students' behaviour towards etno-STEM: instruments for students of etno-STEM based science education. In Journal of Physics: Conference Series (Vol. 1567, No. 4, p. 042021). IOP Publishing.

Saputra, V. H., \& Pasha, D. (2021). Comics as Learning Medium During the Covid-19 Pandemic. 4(February), 330-334.

Saputra, V. H., \& Permata, P. (2018). Media Pembelajaran Interaktif Menggunakan Macromedia Flash Pada Materi Bangun Ruang. WACANA AKADEMIKA: Majalah Ilmiah Kependidikan, 2(2), 116. https://doi.org/10.30738/wa.v2i2.3184 
Saputra, V. H., Pasha, D., \& Afriska, Y. (2020). Design of English Learning Application for Children Early Childhood. Proceeding International Conference on Science and Engineering, 3(April), 661-665.

Saputro, B., \& Susilowati, A. T. (2019). Effectiveness of learning management system (LMS) on in-network learning system (Spada) based on scientific. Journal for the Education of Gifted Young Scientists, 7(3), 481-498.

Sulistiani, H., \& Saputra, V. H. (2020). Penerapan Codeigniter Dalam Pengembangan Sistem Pembelajaran Dalam Jaringan Di SMK 7 Bandar Lampung. Jurnal CoreIT: Jurnal Hasil Penelitian Ilmu Komputer Dan Teknologi Informasi, 6(2), 89-95.

Sulistiani, H., Darwis, D., Silaen, D. S. M., \& Marlyna, D. (2020). PENGEMBANGAN MEDIA PEMBELAJARAN AKUNTANSI BERBASIS MULTIMEDIA (STUDI KASUS: SMA BINA MULYA GADING REJO, PRINGSEWU). Jurnal Komputer dan Informatika, 15(1), 127-136..

Very, V. H. S., \& Pasha, D. (2021). Komik Berbasis Scientific Sebagai Media Pembelajaran di Masa Pandemik Covid-19. SJME (Supremum Journal of Mathematics Education), 5(1).

Wicaksana, M. F., Kurniasari, N., \& Sudiatmi, T. (2021). Learning Machine System (LMS) SPADA Untuk Adaptasi Pengajaran Online. Linguista: Jurnal Ilmiah Bahasa, Sastra, dan Pembelajarannya, 5(1), 57-67. 